\title{
Mechanical Properties of the Hard Sandstone Fracture Surface under Hydrochemical Corrosion
}

\author{
Bin-wei Xia $\mathbb{D},{ }^{1,2}$ Ming-xiang $X u,{ }^{1,2}$ and Chao $\operatorname{Pan}^{1,2}$ \\ ${ }^{1}$ State Key Laboratory of Coal Mine Disaster Dynamics and Control, Chongqing University, Chongqing 400044, China \\ ${ }^{2}$ State and Local Joint Engineering Laboratory of Methane Drainage in Complex Coal Gas Seam, Chongqing University, \\ Chongqing 400044, China
}

Correspondence should be addressed to Bin-wei Xia; xbwcqu@163.com

Received 18 January 2019; Revised 8 March 2019; Accepted 27 March 2019; Published 2 May 2019

Academic Editor: Kantesh Balani

Copyright (C) 2019 Bin-wei Xia et al. This is an open access article distributed under the Creative Commons Attribution License, which permits unrestricted use, distribution, and reproduction in any medium, provided the original work is properly cited.

\begin{abstract}
To realize a quantitative expression of change laws of the fracture surface shear strength with hydrochemical damage and to obtain optimal weakening effect of solution on the fracture surface strength, hard roof sandstone specimens containing hydraulic fracture surfaces from the Tashan Coal Mine located in Datong were subjected to a shear test after corrosion using solutions at different concentrations. The relational expression between shear strength and porosity of the fracture surface was established, and new damage parameters were introduced to describe the evolution laws of the shear strength of sandstone specimens with change in test conditions. Results were as follows. (1) Under sealed hydrochemical environment, corrosion effect on sandstone strengthened, and porosity and roughness gradually increased with increasing solution concentration and soaking time. (2) At a solution concentration of $3 \%-10 \%$, shear strength and roughness of the fracture surface initially increased and then decreased. Hydrochemical solution concentration and action time were important factors that caused strength attenuation of the fracture surface. (3) When the solution concentration was greater than 3\%, the roughness of the fracture surface increased with corrosion time, but its strength showed the tendency to stabilize. The shear strength of the fracture surface increased with shear displacement at a concentration of $5 \%$. The study results can provide a new idea for strong strata pressure control through ground hydrofracturing hard roof.
\end{abstract}

\section{Introduction}

Geological conditions for the occurrence of coal seams in China are very complicated, where coal seams on the difficult-to-collapse hard roof in the overlying strata account for approximately one-third [1]. The difficult-to-collapse hard roof of the Tashan Coal Mine in Datong features many strata, large thickness, and high stratum height. It experiences largearea hanging in the borehole operation process, and intense periodic weighting occurs once it collapses, thereby causing coal mining accidents $[2,3]$. Strong strata pressure behavior is prominent during the mining period of Carboniferous super-thick coal seam. The field test results showed that this problem cannot be solved only by elevating the supporting strength. Thus, a new challenge is formed for roof control.

In recent years, domestic and foreign scholars have achieved progress in research on the influences of solutions on rock mechanical properties. However, these studies mainly focused on failure characteristics under acidification effect on complete specimens as well as parameter analysis. Xinrong Liu [4] and Wen Yuan [5] studied the parametric change laws and porosity evolution laws of sandstones under the effect of drying and wet cycles at different $\mathrm{pH}$ values. The sandstone strength declined with increasing frequency of water-rock cycles. In the early phase of the drying and wetting cycles, the sandstone specimen was significantly influenced and the strength declined to a great extent. Subsequently, the influence of cyclic action was weakened and the strength declined to a relatively small extent. Liang Zhang et al. [6] conducted conventional uniaxial and triaxial compression tests of sandstone specimens under drying and wetting cyclic actions in the acid environment. All mechanical parameters of argillaceous sandstone significantly declined after the first saturation compared with the situation in which the influence of drying and wetting cycles was absent. As the drying and wetting cycles increased, 
the decrement gradually slowed down. Wen Yuan et al. [7] conducted uniaxial and triaxial tests of sandstone specimens after different drying and wetting cycles in acid and alkaline environments to determine their internal cohesive force and internal frictional angle. Then, they obtained the change of sandstone shear strength with cycle index. Aggravation of sandstone shear strength was the most serious in the acid environment, followed by alkaline environment and neutral environment. Hongwei Deng et al. [8] conducted a cyclic test of freezing and thawing under $\mathrm{H}_{2} \mathrm{SO}_{4}, \mathrm{NaOH}, \mathrm{NaCl}$, and water conditions and tested the porosity of sandstone specimens after cycles of freezing and thawing, with the red sandstone in Shandong as an example. After cycles of freezing and thawing at different times, rock porosity distribution underwent evident changes. As the cycle index of freezing and thawing increased, the rock tensile strength declined. Shengjun Miao et al. [9] conducted uniaxial and triaxial compression tests and splitting test of granite specimens after erosion using different acid solutions. After treatment using acid solution, most parameters of granite declined to a certain degree. Moreover, the parameter declined greatly when the $\mathrm{pH}$ value was small or when the flow velocity was great.

The porosity and mineral composition of the rock will experience changes to different degrees after chemical corrosion. Therefore, the influence on rock mechanical properties cannot be neglected. Xie et al. [10] conducted conventional triaxial and rheological tests of porous limestone under the natural state and that after chemical corrosion. They also analyzed the influence of chemical corrosion on porosity change and ageing mechanical properties of limestones. X. T. Feng et al. [11] systematically studied the influence of corrosion on rock mechanical properties and believed that chemical corrosion weakened the bonding between rock mineral particles at a microscopic scale and corrosion effect on mineral particles or crystals while causing attenuation of rock mechanical characteristics at a macroscopic scale. N. Li et al. [12] used water-rock reaction rate to express chemical damage process of sandstone caused by corrosion, established the corresponding chemical corrosion-induced damage model, and predicted the strength and elasticity modulus of sandstone under chemical corrosion at different times.

Hydrochemical corrosion can also affect shear strength and crack propagation of the rock. Thus, B. K. Atkinson et al. [13] studied the influences of different water solutions on the crack propagation rate of quartz materials through the experiment. Chemical composition had controlling effect on crack propagation, and ductile damage value under wet conditions was lower and with faster crack propagation than that under dry conditions. Li Peng [14] carried out shear strength tests under different erosion conditions using solutions and analyzed the influence of action on sandstone microstructure. The chemical kinetics method was used by introducing rock hydrochemical damage degree to simulate the time-dependent process of sandstone damage degree under given hydrochemical environmental conditions to predict evolution laws of its shear strength.

These studies on the corrosion effect of solution on sandstone mainly focused on the mineral particles of sandstone specimens, porosity change, and mechanical characteristics. Pad-acid injection through surface hydrofracturing mainly aimed to generate cracks at target strata, thereby changing the mechanical properties of the fracture surface through the corrosion effect of acid liquor on rock fracture surface and reducing roof strata strength. A quantitative expression of change laws of the shear strength of the fracture surface with hydrochemical damage can provide a theoretical basis for site construction. Therefore, a study on strength parameters of rock fracture surface after corrosion must be carried out.

On this basis, hard roof sandstone specimens containing hydraulic fracture surfaces in the Tashan Coal Mine of Datong were taken as the study objects. A magnetic resonance imaging (MRI) test system and 3D laser scanner were used to analyze change laws of sandstone porosity and roughness of its fracture surface before and after corrosion. A shear test of the postcorrosion specimen was carried out, shear strength and corrosion degree of the fracture surface under different conditions were discussed, and rock hydrochemical damage parameters were introduced to quantitatively describe the change process of shear strength of the sandstone fracture surface with damage. The obtained results provided a new idea for quantitatively studying the influence of hydrochemical action on mechanical characteristics of the rock fracture surface and for the hard roof weakening technology by surface hydrofracturing.

\section{Water-Rock Chemical Reaction Mechanism}

The main mineral compositions in the sandstone hard roof include quartz, feldspar, mica, and rock fragments as seen in Table $1 . \mathrm{F}^{-}$in the solution forms a complex together with $\mathrm{Al}, \mathrm{Si}$, and other ingredients in the specimen, dissolving the $\mathrm{Al}, \mathrm{Si}$ compounds in the specimen and transforming the rock microstructure. These reactions above are as follows. HF and sandstone minerals form a new substance, which will react with $\mathrm{HF}$ as the third mineral [15]:

$$
\begin{gathered}
\mathrm{HF}+\mathrm{H}_{2} \mathrm{O}=\mathrm{H}_{3} \mathrm{O}^{+}+\mathrm{F}^{-} \\
\mathrm{SiF}_{4}+2 \mathrm{HF}=\mathrm{SiF}_{6}^{2-}+2 \mathrm{H}^{+}
\end{gathered}
$$

As $\mathrm{HF}$ is in incomplete ionization, silicate is dissolved when HF concentration is high; and silicon hydroxide sediment (silica gel) is generated under low concentration of HF. The chemical reaction equations are as follows, respectively:

$$
\begin{array}{r}
\mathrm{SiO}_{2}+6 \mathrm{HF}=\mathrm{H}_{2} \mathrm{SiF}_{6}+2 \mathrm{H}_{2} \mathrm{O} \\
\mathrm{H}_{2} \mathrm{SiF}_{6}+4 \mathrm{H}_{2} \mathrm{O}=\mathrm{Si}(\mathrm{OH})_{4}+6 \mathrm{HF} \\
6 \mathrm{HF}+\mathrm{Si}(\mathrm{OH})_{4}=\mathrm{H}_{2} \mathrm{SiF}_{6}+4 \mathrm{H}_{2} \mathrm{O}
\end{array}
$$

The solubility product of fluoride and fluosilicate depends on the concentrations of $\mathrm{Ca}, \mathrm{Mg}$, and $\mathrm{Na}$ ions, etc. in the sandstone. When the solubility product is lower than the solubility limit, no sediment of fluoride and fluosilicate will be generated, with feldspar generating a large quantity of sediments in the residual solution. Reactions of HF with quartz, feldspar, etc. are as follows [16]: 
TABLE 1: Mineral composition analysis of sandstone specimens.

\begin{tabular}{lccccc}
\hline Mineral compositions & Clay mineral & $\mathrm{SiO}_{2}$ & $\mathrm{Al}_{2} \mathrm{O}_{3}$ & $\mathrm{MgO}$ & $\mathrm{CaO}$ \\
\hline Content $(\%)$ & $12.6 \sim 18.6$ & $72 \sim 75.9$ & $12.7 \sim 15.2$ & $0.15 \sim 0.24$ & $0.29 \sim 0.42$ \\
\hline
\end{tabular}

Reaction of HF with quartz is as follows:

$$
\mathrm{SiO}_{2}+6 \mathrm{HF}=\mathrm{H}_{2} \mathrm{SiF}_{6}+2 \mathrm{H}_{2} \mathrm{O}
$$

Reaction of HF with feldspar is as follows:

$$
\begin{aligned}
\mathrm{NaALSi}_{3} \mathrm{O}_{8}+16 \mathrm{HF} & =\mathrm{Na}^{+}+\mathrm{ALF}_{3}+3 \mathrm{SiF}_{4}+8 \mathrm{H}_{2} \mathrm{O} \\
\mathrm{KALSi}_{3} \mathrm{O}_{8}+16 \mathrm{HF} & =\mathrm{K}^{+}+\mathrm{ALF}_{3}+3 \mathrm{SiF}_{4}+8 \mathrm{H}_{2} \mathrm{O}
\end{aligned}
$$

Reaction of HF with clay mineral is as follows:

$$
\begin{gathered}
\mathrm{AL}_{2} \mathrm{Si}_{2} \mathrm{O}_{5}(\mathrm{OH})_{4}+14 \mathrm{HF}=2 \mathrm{ALF}_{3}+2 \mathrm{SiF}_{4}+9 \mathrm{H}_{2} \mathrm{O} \\
\mathrm{AL}_{2} \mathrm{Si}_{4} \mathrm{O}_{10}(\mathrm{OH})_{2}+22 \mathrm{HF}=2 \mathrm{ALF}_{3}+4 \mathrm{SiF}_{4}+12 \mathrm{H}_{2} \mathrm{O}
\end{gathered}
$$

It can be known from the above analysis that the main mineral compositions in the specimen are corroded and dissolved in the solution, and then the sediments are generated and dissolved again, which leads the internal microstructure of the specimen to change. The macroscopic effect caused by this microstructural change is, namely, reduction of shear strength of the sandstone fracture surface.

\section{Methodology}

3.1. Testing Process and Method. Rock specimens used in the test were standard $40 \mathrm{~mm} \times 40 \mathrm{~mm} \times 40 \mathrm{~mm}$ cubic specimens prepared using the same rock mass. The MRI test of all specimens was carried out, the specimens with approximate porosities were selected, and their porosities were determined to analyze the influence of solution of specimen microstructure. A 3D topographical optical measurement scanner was used to scan the fracture surface, with a number of pixels of 2,000,000, scanning spot pitch of $0.1 \mathrm{~mm}$, and scanning accuracy of $0.02 \mathrm{~mm}$. Scanning was implemented thrice to obtain acceptable scanning data. Software was used to synthesize all scanning results and save the final point cloud data. Subsequently, the specimen was dried in a $105^{\circ} \mathrm{C}$ drying oven for $48 \mathrm{~h}$. Then, it was taken out for cooling. The sandstone specimen was placed in solutions with concentrations of $0 \%$ (pure water), $1 \%, 3 \%$, $5 \%$, and $10 \%$, respectively, for $15 \mathrm{~d}$ and $30 \mathrm{~d}$ soaking, and the soaking process was completely sealed to avoid the contact of hydrochemical solution with external atmosphere during the test process. The test temperature was room temperature, the temperature difference was small in the entire soaking process, and the influence of temperature on the test was not considered. After the specimen was obtained, an MRI test was carried out again to change porosity change laws before and after corrosion. To compare the roughness changes of the same fracture surface, a fixed section was marked as the upper part in the direct shear test, and the mobile section was the lower part. Then, 3D scanning of the fracture surface was carried out. To better compare the change in roughness, the roughness was quantified. The roughness of the intercepted tangent was used to represent the roughness of the structural surface. Roughness along the shear direction was related to shear strength, and the tangential direction is along the shear direction given that roughness has directionality and size effect. After scanning, a contour line was intercepted in the middle of a fracture surface, two lines were intercepted again at the left and right by $1 \mathrm{~mm}$ spacing, 39 contour lines were intercepted on one fracture surface, the roughness profile index $R_{p}$ on each contour line was calculated, and the mean values of all parameters were taken as data of the fracture surface. A direct shear test was carried out in the end, displacement loading control was adopted, the loading rate was $0.2 \mathrm{~mm} / \mathrm{min}$, and the normal stress was $3 \mathrm{MPa}$. Figure 1 shows the testing process and equipment.

3.2. Preparation of Hydrochemical Solutions. A hydrofluoric acid (HF) solution of $40 \%$ concentration was selected for dilution. This test mainly aimed to study the influence of chemical corrosion on sandstone shear strength. Restricted by testing time, solution concentration was enlarged to reflect the corrosion effect of the solution on sandstone within a short time. Solution concentrations were selected as $0 \%$ (pure water), $1 \%, 3 \%, 5 \%$, and $10 \%$. Thus, the concentration range was large for the convenience of observation.

3.3. Specimen Preparation. The specimens used in the test were obtained from hard roof rocks after PermoCarboniferous hydrofracturing in the Tashan Coal Mine in Datong, as shown in Figure 2. The particle size was within $0.1-0.5 \mathrm{~mm}$, and the main compositions were quartz, feldspar, clay minerals, and mica. Discreteness of test results existed due to the individual differences of rock specimens. Then, an MRI test was carried out, and the specimens with approximate porosities were considered. A wet-type machining method was used to cut rock specimens containing hydraulic fracture surfaces into cubic specimens with specifications slightly larger than $40 \mathrm{~mm} \times 40 \mathrm{~mm} \times 40 \mathrm{~mm}$. Six faces of each rock specimen were machined using a grinding machine to obtain end-face flatness, perpendicularity, and parallelism of each specimen that satisfy standards recommended by the International Society for Rock Mechanics (ISRM). Sandpapers $(600,800,1200$, and 2000) were used to conduct graded grinding of the surfaces of each specimen. Parallelism errors of two-end faces were controlled within $0.02 \mathrm{~mm}$, and sandstone specimens after machining were maintained in the natural dry state. To guarantee a relative specimen consistency, all specimens were selected from the same rock mass and the integrity of the fracture surface was maintained undamaged. Figure 3 shows the cubic sandstone specimens. 


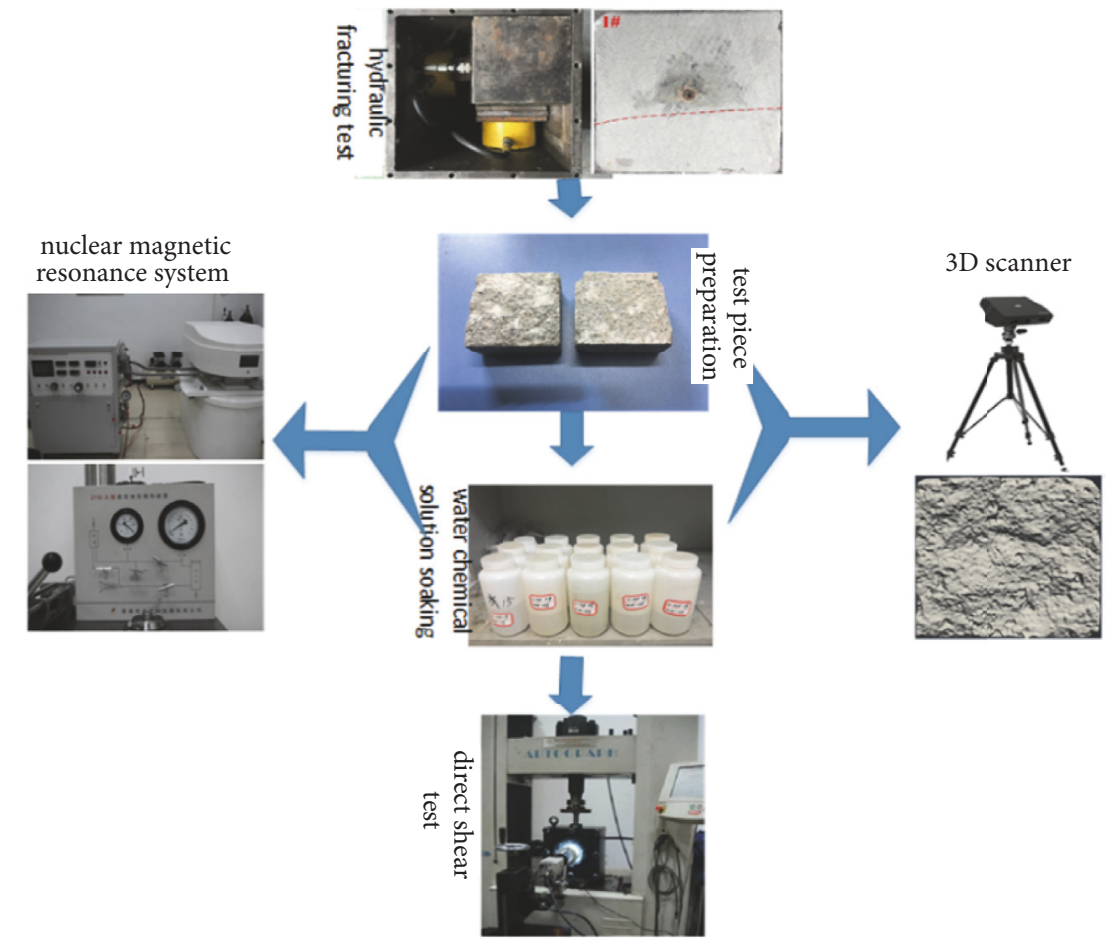

FIGURE 1: Testing process and equipment.

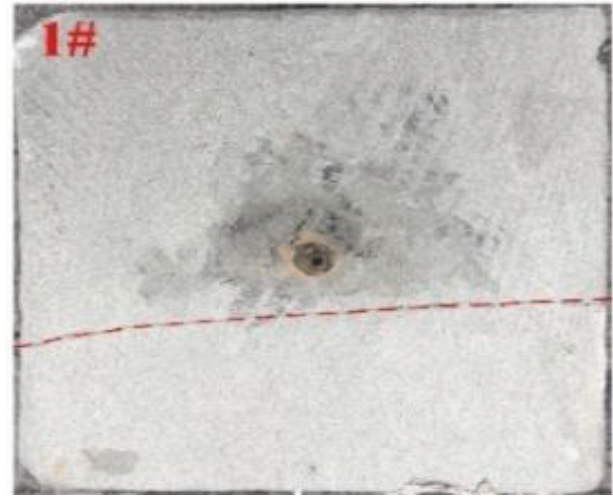

FIGURE 2: Specimen after hydrofracturing.

\section{Result Analysis and Discussion}

4.1. Change Laws of Rock Porosity. Porosity changes of lowerpart sandstone specimens measured after the test was completed are shown in Table 2. The table shows that, under the same hydrochemical environment, the longer the corrosion time, the greater the change of the specimen porosity. Under the same corrosion time, high concentration of the solution led to great change in the specimen's porosity.

4.2. Influence of Hydrochemical Solution of Roughness of the Fracture Surface. Lower fracture surfaces of specimens before and after corrosion were scanned. Figure 4 shows the effect of fracture surfaces before and after $15 \mathrm{~d}$ of corrosion under concentrations of $0 \%$ (pure water), 5\%, and $10 \%$.

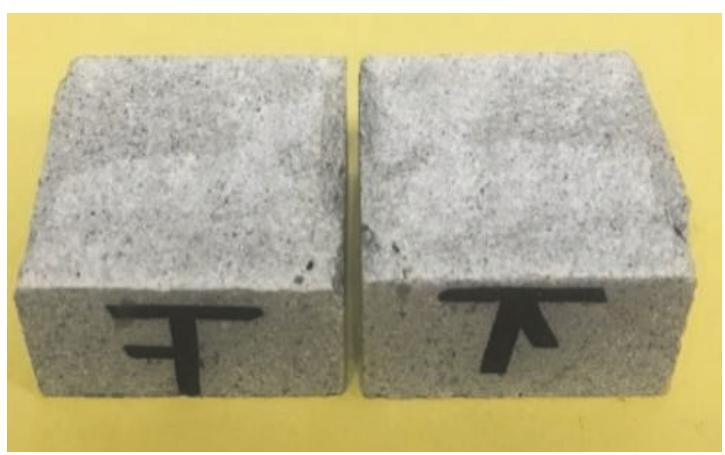

FIGURE 3: Sandstone specimens.

Through a comparison of lower fracture surface scanning graphs under different conditions before and after corrosion, when the solution concentration was $0 \%$ (pure water), relief change of each specimen before and after corrosion was minor. Under $5 \%$ concentration, particles on the fracture surface fell off after corrosion and the overall relief increased with evident projection and depression. Under $10 \%$ concentration, relief on the fracture surface was large with evident corrosion effect, and the framework of the fracture surface was damaged to different degrees. The four corners of the fracture surface were also damaged, thereby influencing the engagement in the closing process.

Figure 5 shows the profile maps of different specimen parts along the shear direction under different conditions. In the $1 \%$ solution, the overall relief degree of the tangent line after corrosion was largely identical to that before corrosion. 
TABLE 2: Comparison chart of porosity changes of specimens under different state conditions before and after corrosion.

\begin{tabular}{lccccc}
\hline $\begin{array}{l}\text { Specimen } \\
\text { number }\end{array}$ & $\begin{array}{c}\text { Hydrochemical } \\
\text { environment (\%) }\end{array}$ & $\begin{array}{c}\text { Specimen } \\
\text { status (d) }\end{array}$ & $\begin{array}{c}\text { Initial } \\
\text { porosity (\%) }\end{array}$ & $\begin{array}{c}\text { Porosity after } \\
\text { soaking (\%) }\end{array}$ & $\begin{array}{c}\text { Porosity change } \\
\text { rate (\%) }\end{array}$ \\
\hline 1 & 0 & 15 & 2.7604 & 4.6299 & 0.6772 \\
2 & 1 & 15 & 2.6137 & 5.1087 & 0.9545 \\
3 & 3 & 15 & 2.8173 & 6.3733 & 1.2622 \\
4 & 5 & 15 & 2.1207 & 7.9512 & 2.7493 \\
5 & 10 & 15 & 2.1363 & 9.0723 & 3.2467 \\
6 & 0 & 30 & 2.3703 & 4.3091 & 0.8180 \\
7 & 1 & 30 & 2.9716 & 5.7341 & 0.9296 \\
9 & 3 & 30 & 2.5059 & 7.6134 & 8.7809 \\
10 & 5 & 30 & 2.9578 & 2.0382 & 1.9687 \\
\end{tabular}
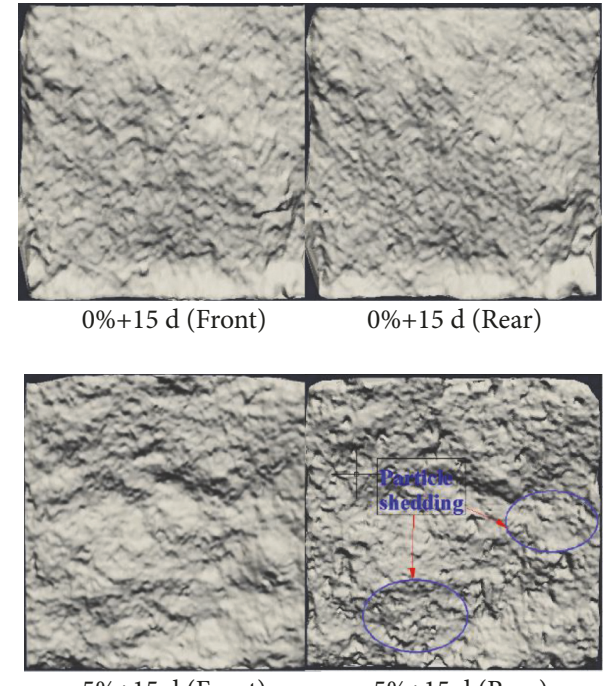

$$
5 \%+15 \mathrm{~d} \text { (Front) } \quad 5 \%+15 \mathrm{~d} \text { (Rear) }
$$

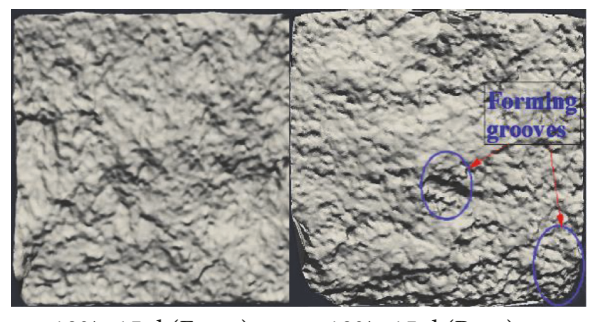

$10 \%+15 \mathrm{~d}$ (Front) $\quad 10 \%+15 \mathrm{~d}$ (Rear)

FIGURE 4: Fracture surface morphologies before and after corrosion.

As the concentration increased, fine particles on the sandstone surface fell off, the rock framework was damaged, new grooves appeared, and the tangent relief degree considerably changed after corrosion. For better comparison of roughness change of the fracture surface, roughness was quantified, and the average roughness of the intercepted tangent was calculated to represent the roughness of the fracture surface. Roughness had directionality and size effect, and the roughness along the shear direction was related to shear strength. Thus, tangential direction was identical to shear moving direction. A total of 39 contour lines were evenly intercepted on the fracture surface after scanning, a quantitative analysis of different tangents was carried out, roughness profile index $\mathrm{R}_{\mathrm{p}}$ on each contour line was calculated, and the average values of all parameters were considered the roughness data of fracture surfaces. $R_{p}$ is calculated using the following formula:

$$
R_{P}=\frac{1}{L} \sum_{i=1}^{n-1} \sqrt{\left(x_{i+1}-x_{i}\right)^{2}+\left(y_{i+1}-y_{i}\right)^{2}} .
$$

Hyun-Sic Jang, Seong-Seung Kang, and Bo-An Jang [17] simulated the relational expression between $\mathrm{R}_{\mathrm{p}}-1$ and JRC using exponential equation (7) in 2014 and achieved favorable correlation $\left(\mathrm{R}^{2}=0.973\right)$.

$$
J R C=65.9\left(R_{P}-1\right)^{0.0302}-9.65 .
$$

Roughness profile indexes $R_{p}$ of the contour lines on fracture surfaces of 10 specimens were calculated, their average value was obtained to calculate the roughness coefficient, and the fracture surface roughness obtained after the hydrofracturing test was within 14.39-18.05. Figure 6 shows that the roughness indexes of fracture surfaces after corrosion increased to different degrees as the concentration of hydrochemical solution increased.

Roughness differences before and after corrosion were calculated to more intuitively express roughness change tendencies because the roughness indexes of fracture surfaces were not the same before the test. As shown in Figure 7, a negative value indicates that the roughness after corrosion was smaller than that before corrosion. Under concentrations $0 \%$ (pure water) and $1 \%$, the roughness difference value was smaller than 1 when corrosion time was 15 and $30 \mathrm{~d}$. The solution concentration was low, the sandstone corrosion degree was small, and the clastic particles fell off the fracture surface after corrosion. The fracture surface roughness gradually increased with increasing solution concentration. Under 0\%$3 \%$ concentration, roughness did not have any evident change as the reaction time passed and the water-rock reaction tended to be stable.

Under 5\% concentration, the roughness index increased by $22.71 \%$ and $33.56 \%$ when compared with those under 

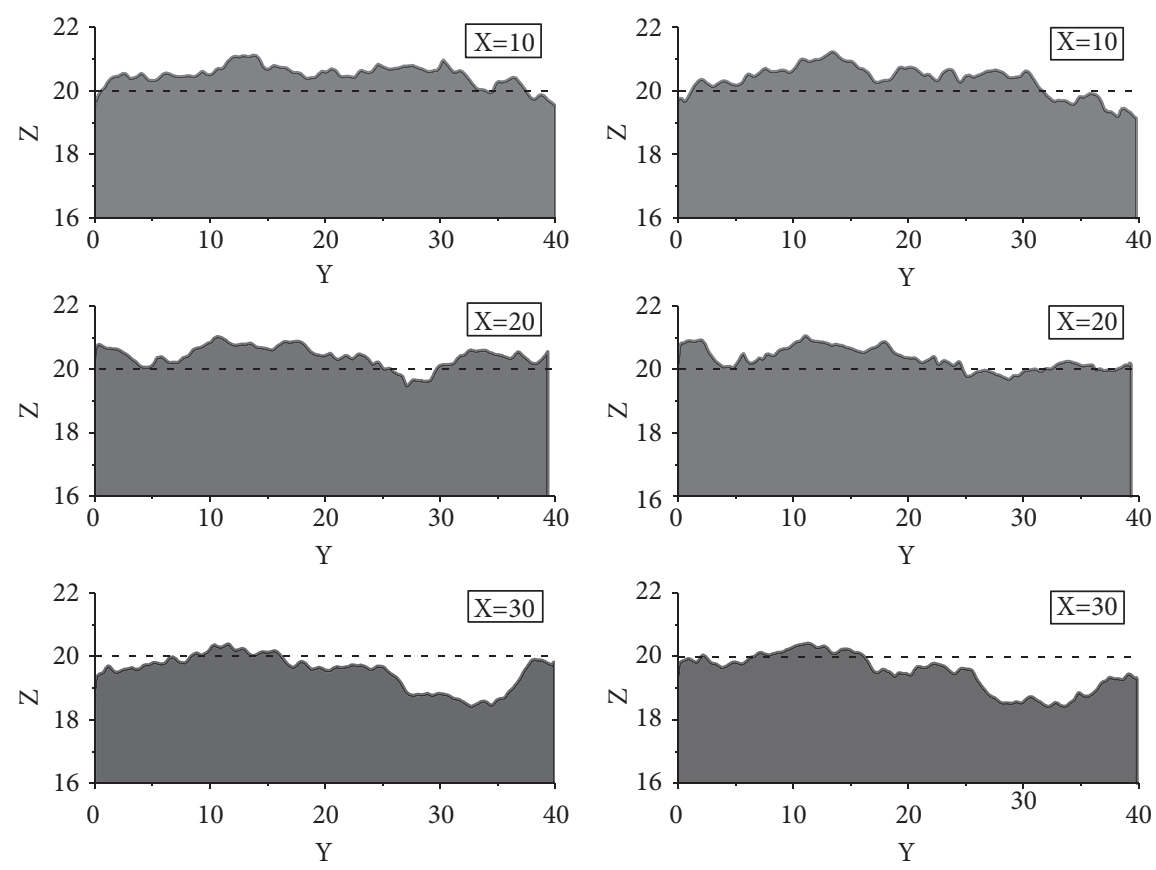

$1 \%+30 \mathrm{~d}$ (Front)

$1 \%+30 \mathrm{~d}$ (Rear)
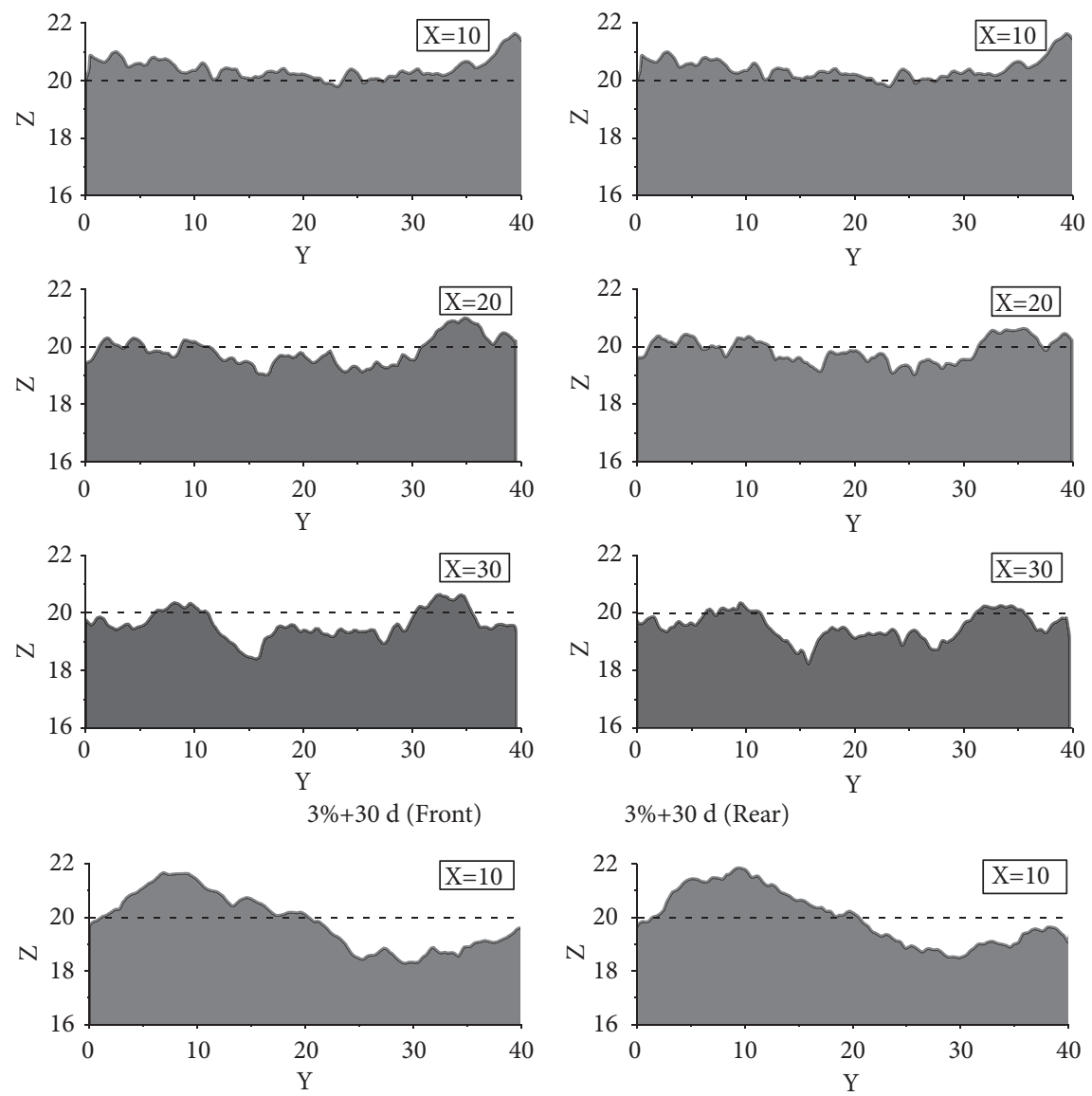

$3 \%+30 \mathrm{~d}$ (Rear)
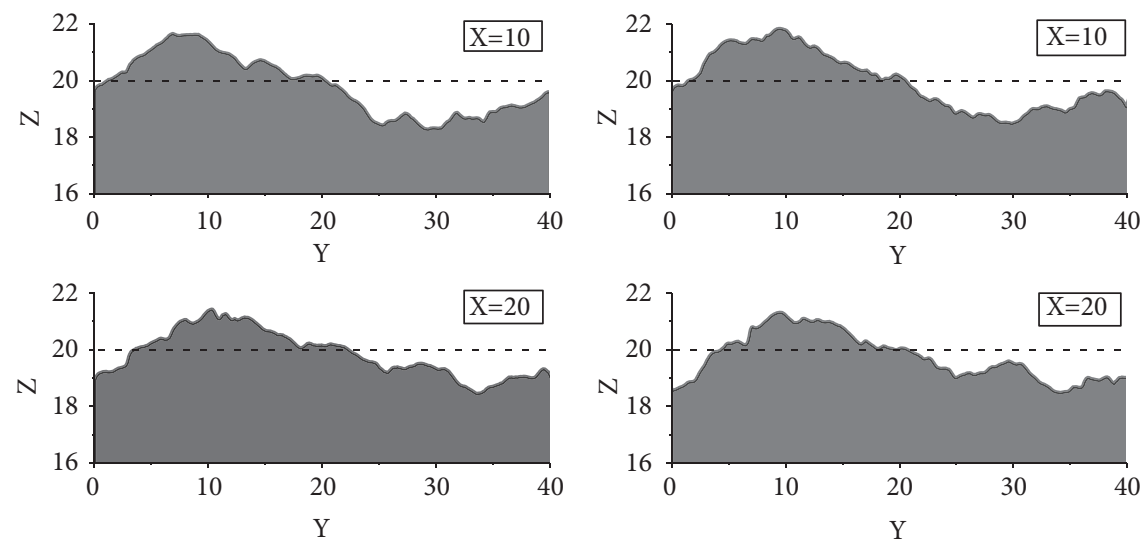

FIGURE 5: Continued. 

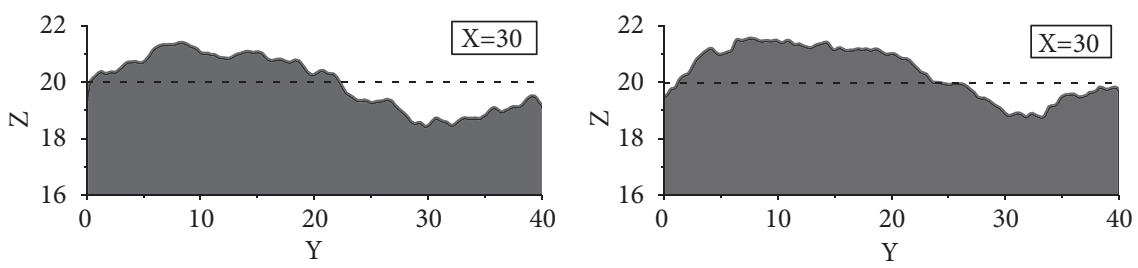

$5 \%+30 \mathrm{~d}$ (Front)

$5 \%+30 \mathrm{~d}($ Rear)
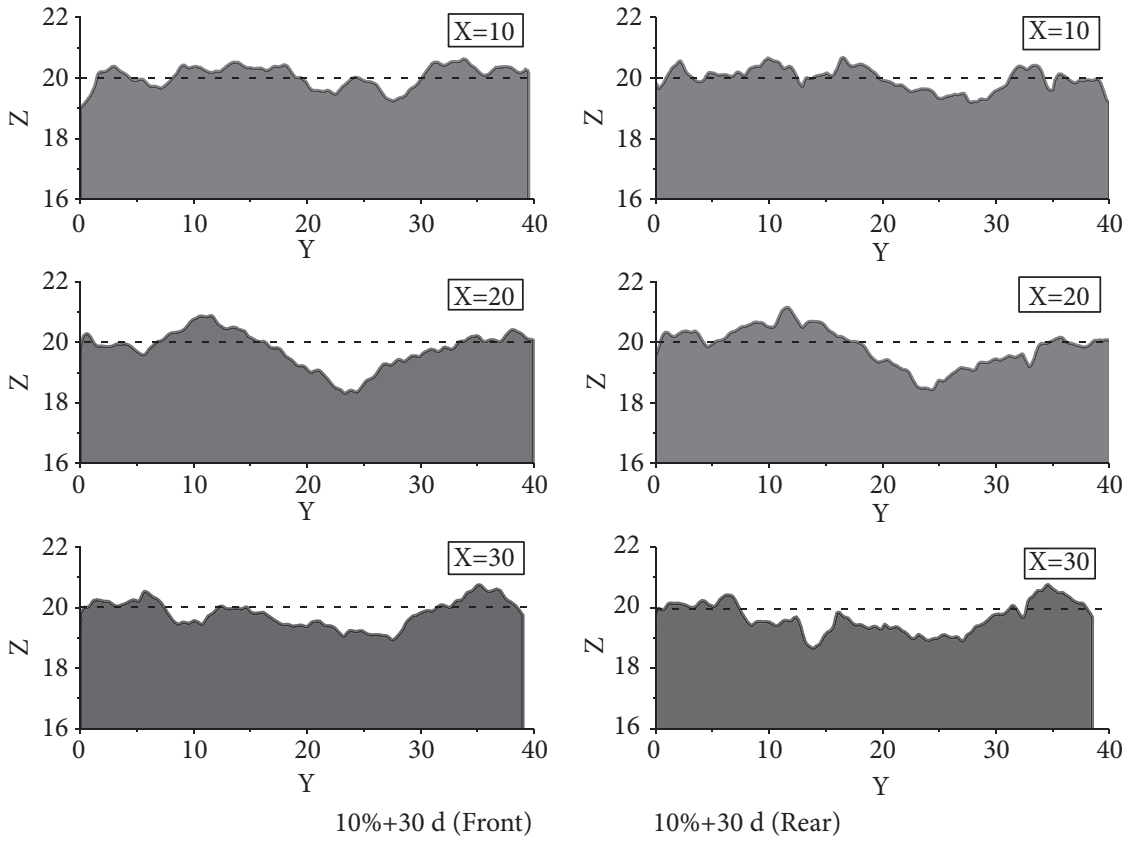

Figure 5: Profile maps of different specimen components along the shear direction before and after reaction with hydrochemical solutions of different concentrations.

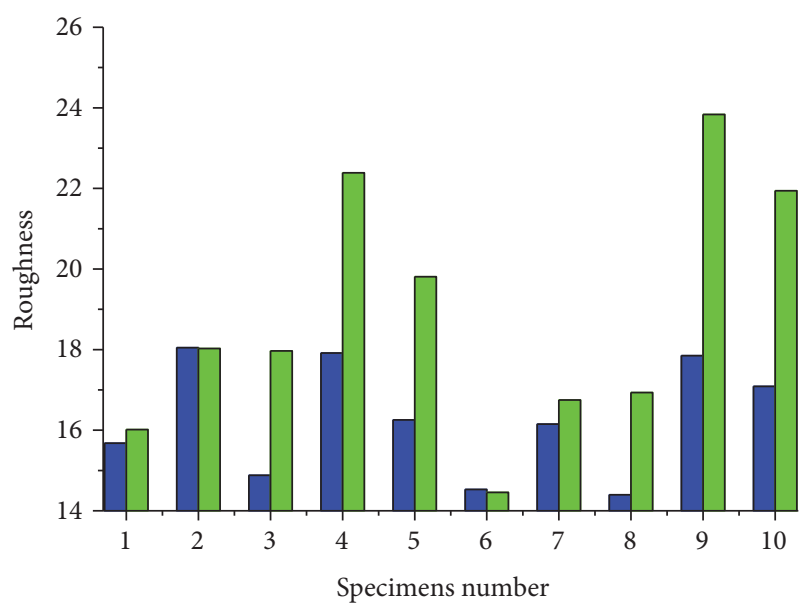

Before corrosion After corrosion

FIgURE 6: Roughness indexes of fracture surfaces before and after corrosion.

the initial state when corrosion proceeded until $15 \mathrm{~d}$ and $30 \mathrm{~d}$, respectively. Under $10 \%$ concentration, the roughness index increased by $21.89 \%$ and $28.38 \%$. The fracture surface

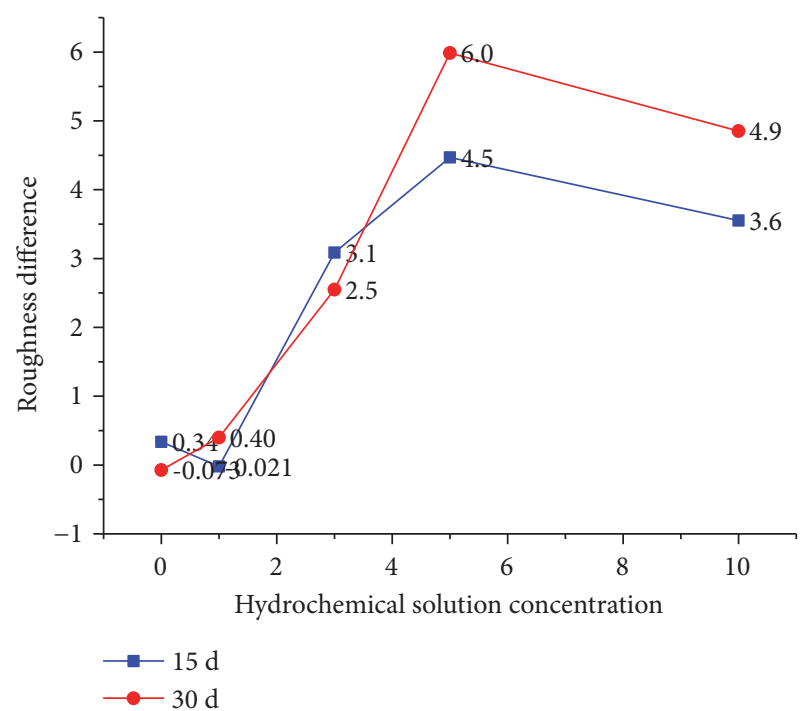

FIGURE 7: Roughness differences before and after corrosion.

roughness gradually increased with time, and the increase in amplitude was enhanced. A large quantity of $\mathrm{HF}$ reacted with minerals in the sandstone, carbonate and clay minerals were 


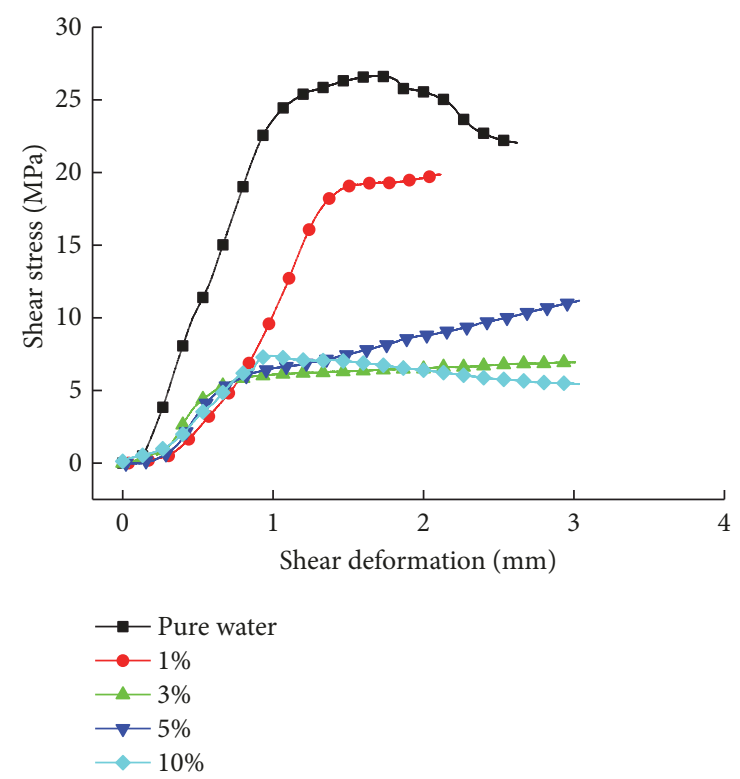

FIGURE 8: Direct shear strength of the specimen after $15 \mathrm{~d}$ corrosion.

reduced, and rock frameworks were corroded to different degrees.

When the concentration of hydrochemical solution is less than $5 \%$, the chemical reaction is more intense with the increase of concentration. The minerals in the specimen are dissolved in the solution or deposited on the fracture surface, resulting in the gradual increase of the roughness of the fracture surface. When the concentration is $5 \%$, the roughness is the largest. After that, the concentration of solution continues to increase, with the HF content increasing, a large number of cements and silicates dissolved, the structure of sandstone destroyed, new fracture surfaces formed, and the roughness changes reduced.

4.3. Analysis of Specimen Shear Strength. Under a certain normal load effect, the asperities on the fracture surface were engaged to different degrees, and different engagement degrees influenced shear strength and tangential deformation of the fracture surface. Figures 8 and 9 show the direct shear strength curves of specimens after 15 and $30 \mathrm{~d}$ of corrosion, respectively. Figure 10 shows the change graphs of shear strengths on fracture surfaces of all specimens after corrosion.

As shown in Figures 8-10, peak shear strengths changed slightly with time after soaking with pure water at 26.67 and $25.97 \mathrm{MPa}$. Under solution concentrations of $1 \%$ and $3 \%$, shear strength declined to a great extent. The strengths declined by $25.5 \%$ and $43.2 \%$ when compared with that in the pure water circumstance at a concentration of $1 \%$. Shear strength declined to half of the original value as the time passed. When the concentration reached 3\%, shear strength reached the minimum value, and then it fluctuated within 5$7 \mathrm{MPa}$. After $30 \mathrm{~d}$ of corrosion, strength slightly declined.

When the concentration was smaller than $3 \%$, the roughness of the fracture surface did not change evidently, indicating that the soaking effect of water on sandstone played a dominant role in the solution. Water molecules

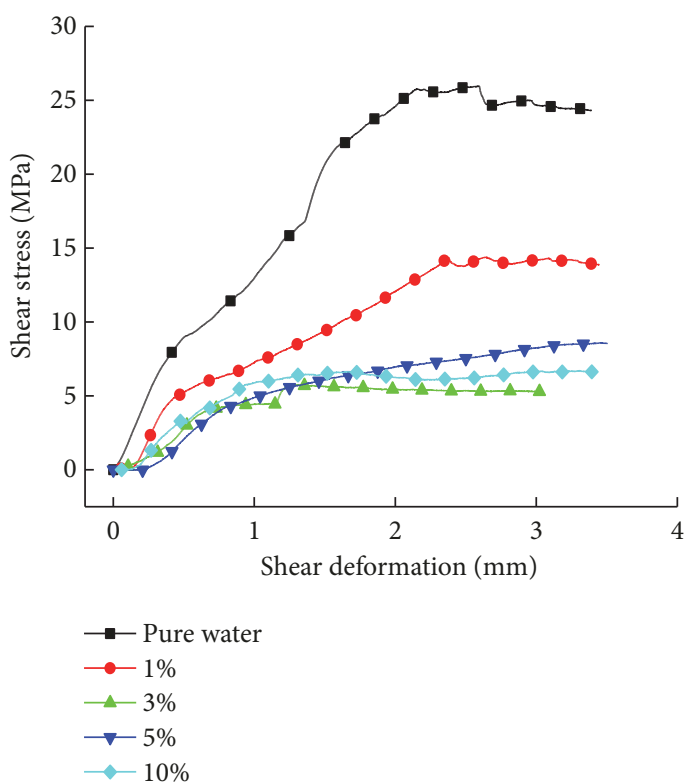

FIGURE 9: Direct shear strength of the specimen after $30 \mathrm{~d}$ corrosion.

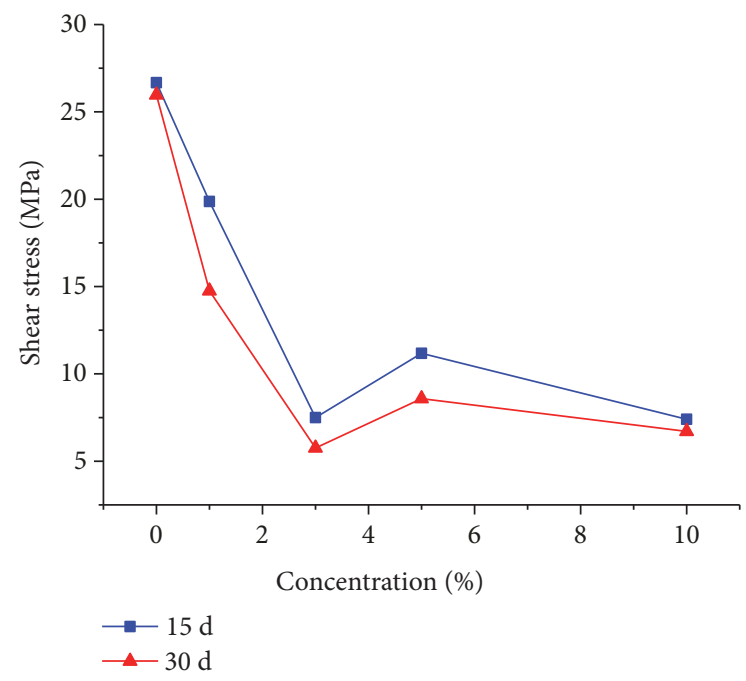

FIgURE 10: Strength after corrosion.

would continuously permeate into the sandstone due to the adsorption effect, and clay minerals in the sandstone would experience softening and argillization when contacting water, thereby reducing the shear strength of the fracture surface. In the shear slipping process, the shear strength of asperities constituted one part of the strength of the fracture surface, and the shear stress was mainly the shear force for asperities at the time.

Under 3\% concentration, shear strength was the minimum, acidification effect was the best, and roughness slightly changed with time. Cements and clay minerals in the sandstone reacted with HF; thus, the fracture surface became rough. At a microscopic scale, the corrosion effect of hydrochemical solution on the sandstone specimen caused changes to its mineral compositions and internal pore structure. At 
a macroscopic scale, the mechanical characteristics of the specimen were degraded, and the roughness of the fracture surface increased.

At $3 \%, 5 \%$, and $10 \%$ concentrations, the peak shear strengths of all fracture surfaces were stabilized at approximately $6 \mathrm{MPa}$. The quartz in the sandstone framework was dissolved and roughness evidently increased with increasing concentration. As the shear displacement increased, the shear strength presented a rising tendency under $5 \%$ concentration; i.e., the final result was due to the increase in the frictional force on the fracture surface. At the time, shear stress was mainly the shear force for asperities and frictional force on the fracture surface.

When the concentration of hydrochemical solution is $3 \%, 5 \%$, and $10 \%$, when the specimens are soaked for 15 days, the peak shear strength of fracture surface is between 7.3 $\mathrm{MPa}$ and $7.5 \mathrm{MPa}$, and the peak shear strength of fracture surface is between $6.3 \mathrm{MPa}$ and $6.7 \mathrm{MPa}$ when they are soaked for 30 days. It can be seen that when the concentration is $3 \%, 5 \%$, and $10 \%$, the peak shear strength of the fracture surface changes little with the increase of the solution concentration, and the corrosion effect tends to be stable. Compared with the concentrations of $0 \%$ and $1 \%$, the peak shear strength decreases greatly. At this time, with the concentration increasing, the peak shear strength does not change significantly, and the strength is the force of shearing micro-convex body. With the increase of the concentration, the more quartz in sandstone skeleton is dissolved, and the roughness of fracture surface increases obviously. The shear strength increases with the increase of shear displacement when the concentration is $5 \%$. That is the ultimate result of the increase of friction on the fracture surface. At this time, the shear stress is mainly the force of the micro-convex body sheared and the friction on the fracture surface.

\subsection{Influence of Hydrochemical Damage on Sandstone Shear} Strength. Appropriate damage variables should be selected to study the damage and describe the influence of damage state change and its influence on the mechanical characteristics of specimens, and appropriate state variables are selected from microscopic and macroscopic angles in common definitions of damage variables $[14,18,19]$. The porosities of rock specimens relatively increased after corrosion using hydrochemical solution, and the internal pore structure also changed. Therefore, porosity change is used to establish damage variables.

Damage variables are as follows:

$$
D=\frac{\phi-\phi_{0}}{1-\phi_{0}} \times 100 \%,
$$

where $\phi_{0}$ is initial porosity and $\phi$ is porosity after corrosion.

Li Peng [14] obtained linear relations of damage variables with cohesive force and internal frictional angle through regression analysis. When the normal force is fixed, the shear strength of the fracture surface is related to damage variables.

$$
\tau=\sigma_{\mathrm{n}} \tan \varphi+c
$$

$$
\begin{aligned}
\varphi & =a_{1} D+a_{2} \\
c & =a_{3} \mathrm{e}^{a_{4} D},
\end{aligned}
$$

where $a_{1}, a_{2}, a_{3}$, and $a_{4}$ are different coefficients; $\sigma_{\mathrm{n}}$ is normal stress; $\varphi$ is internal frictional angle.

In the shear strength study of specimens containing fracture surfaces, the shear strength consists of two parts, namely, JRC-related part and surface friction-related part.

$$
\tau=\sigma_{\mathrm{n}} \tan \varphi_{b}+a_{5} J R C,
$$

where $\sigma_{\mathrm{n}}$ is normal stress; $\varphi_{b}$ is basic frictional angle; $a_{5}$ is coefficient under different states.

The chemical and physical actions exist in the water-rock reaction. In the aspect of physical action, the particles fall off the fracture surface, the roughness index is changed due to the dissolution effect of the solution on the rock, and the splitting effect is generated on the micropores. In terms of chemical action, water-rock reaction changes the rock mineral compositions and porous fracture structure. Their combined action finally gives rise to the strength change of the rock fracture surface.

In full consideration of damage variable and fracture surface roughness, their relationships with the shear strength of the sandstone fracture surface are as follows:

15 d specimens:

$$
\tau=171.9445 e^{-110.032 D}+0.4119 J R C(0.9463)
$$

$30 \mathrm{~d}$ specimens:

$$
\tau=144.2008 e^{-95.6043 D}+0.3129 J R C(0.9969)
$$

All specimens:

$$
\tau=154.4041 e^{-101.4002 D}+0.3557 J R C(0.9587)
$$

Figure 11 can be obtained according to the formula after all test data are fitted. Table 3 shows a comparison between the calculated value and measured value.

\section{Conclusions}

A self-developed coal rock shear test device was utilized to conduct indoor shear test after corrosion using solutions at different concentrations. Roughness and porosity changes of fracture surfaces were analyzed. The relationship between shear strength of the hydrofracturing surface and sandstone corrosion degree was discussed, and the following main conclusions were drawn:

(1) Under sealed hydrochemical environment, corrosion effect was gradually enhanced, and the porosity and roughness of each sandstone specimen gradually increased as the solution concentration or soaking time increased. The fracture surface roughness reached the maximum value under $5 \%$ concentration 
TABle 3: Specimen shear strengths under different states.

\begin{tabular}{lccc}
\hline \multirow{2}{*}{ Hydrochemical environment (\%) } & Specimen status $(\mathrm{d})$ & \multicolumn{2}{c}{ Shear strength } \\
Calculated value $(\mathrm{MPa})$ \\
\hline 0 & & Measured value (MPa) & 27.666 \\
0 & 15 & 26.67 & 25.612 \\
1 & 30 & 25.97 & 17.905 \\
1 & 15 & 19.87 & 14.495 \\
3 & 30 & 14.75 & 10.169 \\
3 & 15 & 7.49 & 6.7845 \\
5 & 30 & 5.76 & 8.1872 \\
5 & 15 & 11.18 & 8.8302 \\
10 & 30 & 8.58 & 7.1632 \\
10 & 15 & 7.4 & 7.9666 \\
\hline
\end{tabular}

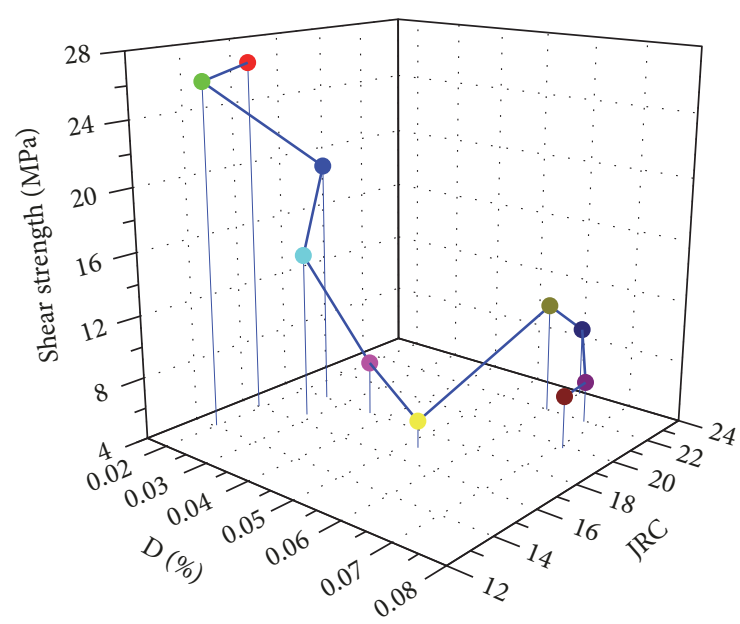

FIGURE 11: Relationships of specimen strength with D and JRC.

(2) When the concentration of the solution was larger than $3 \%$, the peak strength of the fracture surface tended to be stable, the fracture surface roughness was the maximum under 5\% concentration, and the shear strength increased with the shear displacement

(3) The porosity change of the specimen after chemical corrosion was closely related to its strength. Porosity could be used to quantitatively describe the hydrochemical corrosion degree of the sandstone specimen, based on which chemical damage parameters describe the shear strength of the sandstone fracture surface with roughness

\section{Data Availability}

The data used to support the findings of this study are available from the corresponding author upon request.

\section{Conflicts of Interest}

The authors declare that they have no conflicts of interest regarding the publication of this paper.

\section{References}

[1] Y. Feng and H. Kang, "Test on hard and stable roof control by means of directional hydraulic fracturing in coal mine," Chinese Journal of Rock Mechanics and Engineering, vol. 31, no. 6, pp. 1148-1155, 2012.

[2] H. S. B. Düzgün, "Analysis of roof fall hazards and risk assessment for Zonguldak coal basin underground mines," International Journal of Coal Geology, vol. 64, no. 1-2, pp. 104115, 2005.

[3] M. Gu and K. K. Mohanty, "Effect of foam quality on effectiveness of hydraulic fracturing in shales," International Journal of Rock Mechanics and Mining Sciences, vol. 70, pp. 273-285, 2014.

[4] X.-R. Liu, W. Yuan, Y. Fu, Z.-J. Wang, L.-W. Zhu, and Y.-K. Xie, "Deterioration rules of shear strength in sandstones under wetting and drying cycles in acid and alkali environment," Chinese Journal of Geotechnical Engineering, vol. 39, no. 12, pp. 2320-2326, 2017.

[5] W. Yuan, X. Liu, and Y. Fu, Strength Deterioration and Chemical Mechanism of Sandstone Under Dry-Wet Cycles in Acid and Alkali Environment, Chongqing University, 2017.

[6] Z. Liang, L. Xin-Rong, F. Yan, and W. Zi-Juan, "Mechanical properties of argillaceous sandstone under wet and dry cycle in acid environment," Electronic Journal of Geotechnical Engineering, vol. 19, pp. 1433-1446, 2014.

[7] W. Yuan, X. Liu, and Y. Fu, "Chemical thermodynamics and chemical kinetics analysis of sandstone dissolution under the action of dry-wet cycles in acid and alkaline environments," Bulletin of Engineering Geology and the Environment, pp. 1-9, 2017.

[8] H. W. Deng, C. F. Dong, J. L. Li, K. P. Zhou, W. G. Tian, and J. Zhang, "Experimental study on sandstone freezing-thawing damage properties under condition of water chemistry," Applied Mechanics and Materials, vol. 608-609, pp. 726-731, 2014.

[9] S. Miao, M. Cai, Q. Guo, P. Wang, and M. Liang, "Damage effects and mechanisms in granite treated with acidic chemical solutions," International Journal of Rock Mechanics and Mining Sciences, vol. 88, pp. 77-86, 2016.

[10] S. Y. Xie, J. F. Shao, and W. Y. Xu, "Influences of chemical degradation on mechanical behaviour of a limestone," International Journal of Rock Mechanics \& Mining Sciences, vol. 48, no. 5, pp. 741-747, 2011. 
[11] X.-T. Feng, S. Chen, and S. Li, "Effects of water chemistry on microcracking and compressive strength of granite," International Journal of Rock Mechanics and Mining Sciences, vol. 38, no. 4, pp. 557-568, 2001.

[12] L. Ning, Z. Yunming, S. Bo, and S. Gunter, "A chemical damage model of sandstone in acid solution," International Journal of Rock Mechanics and Mining Sciences, vol. 40, no. 2, pp. 243-249, 2003.

[13] B. K. Atkinson and P. G. Meredith, "Stress corrosion cracking of quartz: a note on the influence of chemical environment," Tectonophysics, vol. 77, no. 1-2, pp. 1-11, 1981.

[14] P. Li, J. Liu, G.-H. Li, J.-B. Zhu, and S.-G. Liu, "Experimental study for shear strength characteristics of sandstone under water-rock interaction effects," Rock and Soil Mechanics, vol. 32, no. 2, pp. 380-386, 2011.

[15] N. Kalia and V. Balakotaiah, "Modeling and analysis of wormhole formation in reactive dissolution of carbonate rocks," Chemical Engineering Science, vol. 62, no. 4, pp. 919-928, 2007.

[16] N. Kalia and G. Glasbergen, "Wormhole formation in carbonates under varying temperature conditions," in Proceedings of the 8th European Formation Damage Conference, vol. 35(2), pp. 22-28, Society of Petroleum Engineers, Scheveningen, The Netherlands, 2009.

[17] H.-S. Jang, S.-S. Kang, and B.-A. Jang, "Determination of joint roughness coefficients using roughness parameters," Rock Mechanics and Rock Engineering, vol. 47, no. 6, pp. 2061-2073, 2014.

[18] Q. Zhang, G. Yang, and J. Ren, "Study of damage variable and constitutive equation of rock," Chinese Journal of Rock Mechanics and Engineering, vol. 22, no. 1, pp. 30-34, 2003.

[19] T. Yu and J. Qian, Damage Theory and Its Application, National Defence Industry Press, Beijing, China, 1993. 


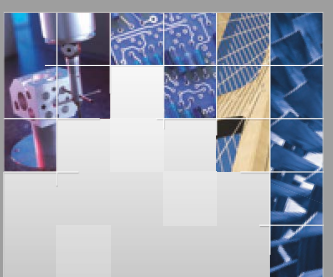

\section{Enfincering}
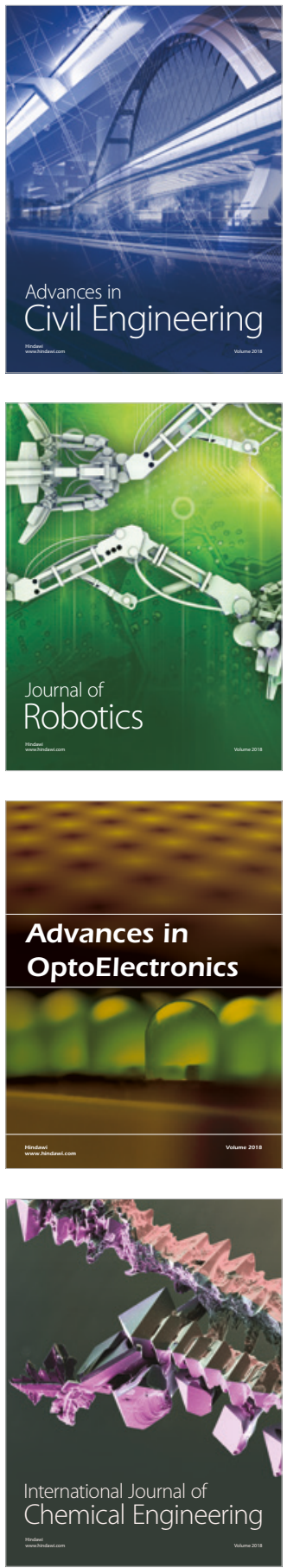

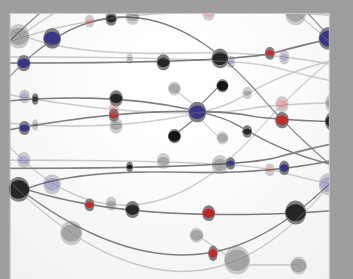

\section{Rotating \\ Machinery}

The Scientific World Journal

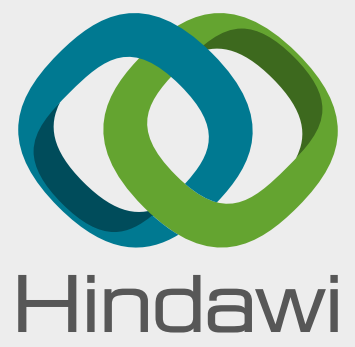

Submit your manuscripts at

www.hindawi.com
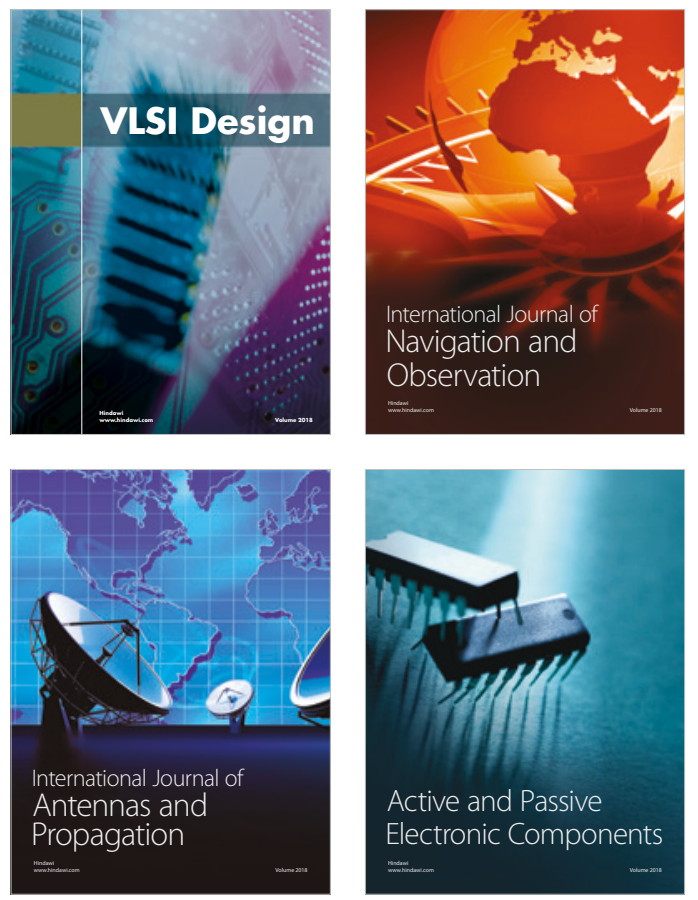
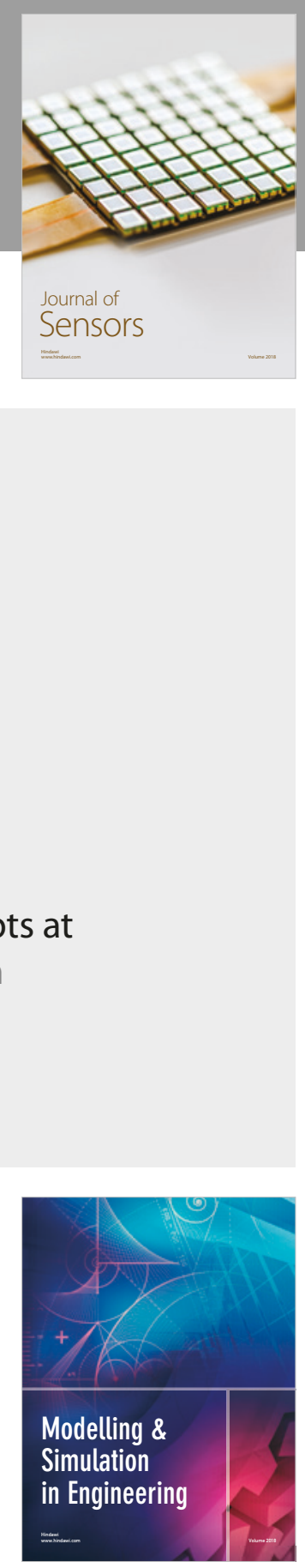

\section{Advances \\ Multimedia}
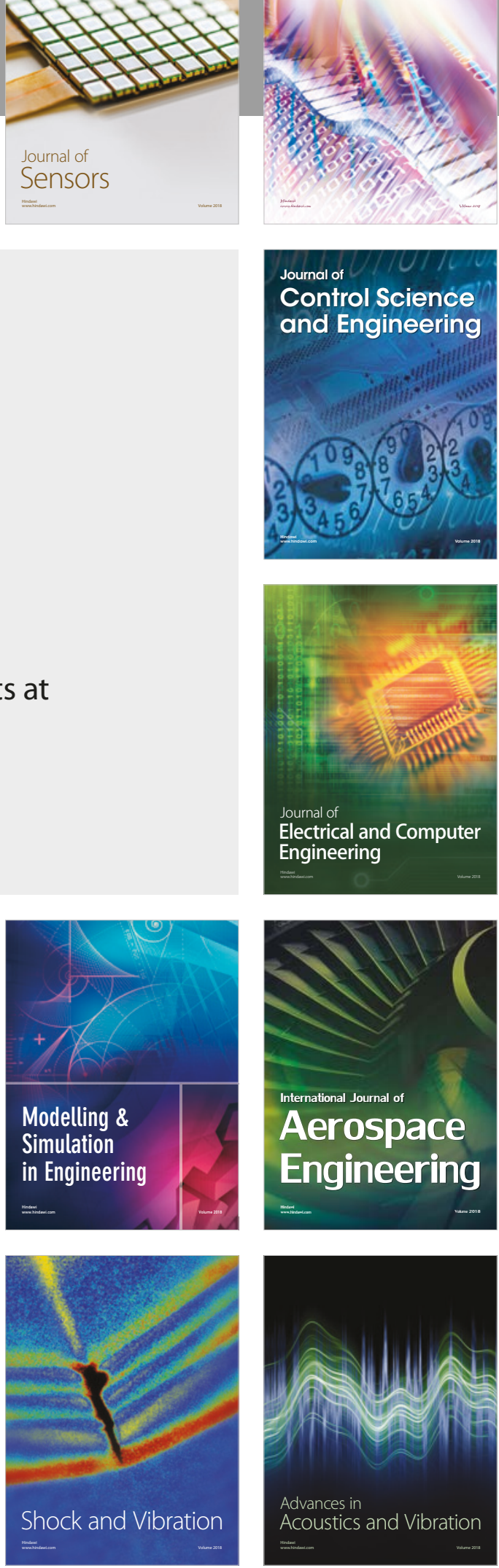